\title{
CORRELATION BETWEEN THE FREEZE FRACTURE APPEAR- ANCE AND POLYPEPTIDE COMPOSITION OF THYLAKOID MEMBRANES IN BARLEY
}

\author{
by \\ OTTO MACHOLD, \\ DAVID J. SIMPSON \\ and \\ GUNILLA HØYER-HANSEN \\ Department of Physiology, Carlsberg Laboratory \\ Gamle Carlsberg Vej 10, DK-2500 Copenhagen, Valby \\ and \\ Zentralinstitut für Genetik und Kulturpflanzenforschung \\ der Akademie der Wissenschaften der DDR, 4325 Gatersleben, DDR
}

Keywords: Chlorina-f2, chlorophyll-protein complexes, chloroplast membranes, electron microscopy, SDS-gel electrophoresis, subtilisin, trypsin

Thylakoids isolated and purified from wild-type barley chloroplasts were treated to remove polypeptides without destroying the membrane structure. The polypeptide compositions of such basic membranes were determined by SDS-polyacrylamide gel electrophoresis and the ultrastructure of the membranes determined in thin sections of fixed material and by freeze-fracturing. Treatments with guanidine hydrochloride, trypsin and subtilisin removed most of the polypeptides except for the chlorophyll-protein complexes. Freeze-fracture particles were observed in the basic membranes, although the size distribution and number per unit area were altered. It is concluded that the chlorophyll-protein complexes are the major components of the freeze-fracture particles present after treatment, and that most of the thylakoid polypeptides are susceptible to proteolytic attack at the membrane surface. The only extraction procedure that removed both chlorophyll-protein complexes (6 M-guanidine thiocyanate) also disintegrated the membranes, resulting in lipid artifact structures. Thylakoids isolated from the chlorina-f2 mutant were more susceptible to disintegration when treated in the same way as wild-type, possibly due to the absence of chlorophyll-protein complex II. 


\section{INTRODUCTION}

Experiments on biological membranes carried out during the past few years have supported the fluid mosaic model of the structure of cell membranes, which postulates that globular proteins are embedded completely or partly in a lipid bilayer (14). The particles revealed by freeze-fracturing are thought to be composed of polypeptides and to represent functional units of the membrane. The addition of isolated integral membrane proteins to artificial lipid bilayers, which lack freeze-fracture particles, causes the appearance of such particles $(6,18)$, thereby supporting the hypothesis that the freeze-fracture particles consist of protein.

It has been proposed that the small particles of the protoplasmic fracture (PF) faces (nomenclature of BRANTON et al., 4) of chloroplast thylakoids are the functional units of photosystem I activity, and that the large particles of the EF faces contain photosystem II activity (3). THORNBER et al. (17) suggested that the two chlorophyll-protein complexes of chloroplast thylakoids are located in different freeze-fracture paticles. These hypotheses have not been proven although subsequent work is not inconsistent with such a model.

The present paper describes experiments designed to remove membrane polypeptides under conditions that preserve membrane structure. The resulting basic membranes (10) were studied by gel electrophoresis and electron microscopy using thin-sectioning and freeze-fracturing. The appearance of the freeze-fractured membranes is correlated with their relatively simple polypeptide composition.

\section{MATERIALS AND METHODS}

\subsection{Plant material}

Wild-type barley (Hordeum vulgare L. cv. Svalövs Bonus) and chlorina- $f 2$ seedlings were grown for 7 days at $20^{\circ} \mathrm{C}$ on tap watermoistened vermiculite under continuous illumination (1500 Iux). Isolation and purification of internal chloroplast membranes were carried out according to the method described by HøYER-HANSEN and SIMPSON (8).

\subsection{Treatment of thylakoids}

After the purified thylakoids had been centrifuged in $25 \mathrm{~mm}$-HEPES, $10 \mathrm{~mm}$-EDTA, the pellet was resuspended in a small volume of distilled water and divided into aliquots containing $15 \mathrm{mg}$ of protein. Guanidine- $\mathrm{HCl}$ or guanidine thiocyanate was added to give a final concentration of $6 \mathrm{M}$ in $0.03 \mathrm{M}$-sodium borate $/ \mathrm{HCl}$ buffer, pH 8.9 and extraction was effected by vigorous shaking in sealed centrifuge tubes for $3 \mathrm{~h}$ at room temperature, using a side-arm mechanical shaker. Trypsin $(20 \mathrm{mg} / 20 \mathrm{ml})$ or subtilisin $(5 \mathrm{mg} / 20 \mathrm{ml})$ treatment was carried out by gentle stirring at room temperature for lh in $0.05 \mathrm{M}-\mathrm{Tris} / \mathrm{HCl}$, pH 7.5 or for $30 \mathrm{~min}$ in $0.03 \mathrm{M}$-sodium borate $/ \mathrm{HCl}, \mathrm{pH} 8.9$ respectively (Table I). Proteolysis was stopped by the addition of $35 \mathrm{mg}$ of the inhibitor phenylmethylsulphonylfluoride (PMSF) dissolved in $0.5 \mathrm{ml}$ of acetone. The treated membranes were pelleted and washed with $10 \mathrm{ml}$ of $8 \mathrm{M}$-urea in the case of guanidine- $\mathrm{HCl}$, trypsin and subtilisin, and distilled water in the case of guanidine thiocyanate. After centrifugation, the pellet was given a final wash in distilled water, recentrifuged and sampled for electron microscopy.

The effect of shaking on the membranes was examined by suspending an aliquot in $20 \mathrm{ml}$ of distilled water and shaking vigorously for $\mathrm{lh}$. Trypsin (type XI, DCC-treated) and PMSF were purchased from Sigma, and subtilisin (type Carlsberg) was the generous gift of Dr. IB SvENDSEN. Guanidine-HCl and guanidine thiocyanate were purchased from Ferak (West Berlin).

\footnotetext{
Abbreviations: $\mathrm{CF}_{1}=$ coupling factor, $\mathrm{CPI}=$ chlorophyll-protein complex $\mathrm{l}, \mathrm{CPII}=$ chlorophyll-protein complex II, CPII-AP = chlorophyll-protein complex II apoprotein, DTT = dithiothreitol, EF = endoplasmic fracture face, $\mathrm{PF}=$ protoplasmic fracture face, HEPES $=\mathrm{N}$-(2-hydroxyethyl)-piperazine-N'-2-ethane sulphonic acid, $\mathrm{ME}=$ mercaptoethanol, $\mathrm{PMSF}=$ phenylmethylsulphonylfluoride, $\mathrm{SDS}=$ sodium dodecyl sulphate.
} 
Table I

Experimental procedure for preparation of basic membranes.

\begin{tabular}{|c|c|c|c|c|}
\hline $\begin{array}{l}\text { Treatment No. } \\
\text { Condition }\end{array}$ & 1 & 2 & 3 & 4 \\
\hline Incubation medium & Guanidine- $\mathrm{HCl}$ & Guanidine-SCN & Trypsin & Subtilisin \\
\hline Volume & $10 \mathrm{ml}$ & $10 \mathrm{ml}$ & $20 \mathrm{ml}$ & $20 \mathrm{ml}$ \\
\hline Concentration & $6 \mathrm{M}$ & $6 M$ & $20 \mathrm{mg}$ & $5 \mathrm{mg}$ \\
\hline Incubation buffer & $\begin{array}{c}0.03 \mathrm{M}-\mathrm{Na}-\mathrm{B} \text { orate } / \mathrm{HCl} \\
\text { pH } 8.9\end{array}$ & $\begin{array}{c}0.03 \mathrm{M}-\mathrm{Na}-\mathrm{Borate} / \mathrm{HCl} \\
\mathrm{pH} 8.9\end{array}$ & $\begin{array}{c}0.05 \mathrm{M}-\text { Tris } / \mathrm{HCl} \\
\mathrm{pH} 7.5\end{array}$ & $\begin{array}{c}0.03 \mathrm{M}-\mathrm{Na}-\mathrm{B} \text { orate } / \mathrm{HCl} \\
\mathrm{pH} 8.9\end{array}$ \\
\hline Incubation time & $3 \mathrm{~h}$ & $10 \mathrm{~min}$ & lh & $30 \mathrm{~min}$ \\
\hline $\begin{array}{l}\text { Conditions during } \\
\text { incubation }\end{array}$ & $\begin{array}{l}\text { High frequency } \\
\text { shaking at } \\
\text { room temperature }\end{array}$ & $\begin{array}{l}\text { High frequency } \\
\text { shaking at } \\
\text { room temperature }\end{array}$ & $\begin{array}{l}\text { Magnetic } \\
\text { stirring at } \\
\text { room temperature }\end{array}$ & $\begin{array}{l}\text { Magnetic } \\
\text { stirring at } \\
\text { room temperature }\end{array}$ \\
\hline Inhibitor & & & $\begin{array}{l}35 \mathrm{mg} \text { PMSF } \\
\text { dissolved in } \\
0.5 \mathrm{ml} \text { acetone }\end{array}$ & $\begin{array}{l}35 \mathrm{mg} \text { PMSF } \\
\text { dissolved in } \\
0.5 \mathrm{ml} \text { acetone }\end{array}$ \\
\hline \multirow[t]{2}{*}{ Post treatments } & $\begin{array}{l}\text { 1. } 10 \mathrm{ml} 8 \mathrm{M} \text {-urea } \\
30 \mathrm{~min} \text { shaking }\end{array}$ & $\begin{array}{l}\text { 1. } 10 \mathrm{ml} \mathrm{H}_{2} \mathrm{O} \\
15 \mathrm{~min} \text { shaking }\end{array}$ & $\begin{array}{l}1.10 \mathrm{ml} 8 \mathrm{M} \text {-urea } \\
30 \mathrm{~min} \text { shaking }\end{array}$ & $\begin{array}{r}\text { 1. } 10 \mathrm{ml} 8 \mathrm{M} \text {-urea } \\
30 \mathrm{~min} \text { shaking }\end{array}$ \\
\hline & $\begin{array}{l}\text { 2. } 20 \mathrm{ml} \mathrm{H}_{2} \mathrm{O} \\
15 \mathrm{~min} \text { shaking }\end{array}$ & $\begin{array}{l}\text { 2. } 10 \mathrm{ml} \mathrm{H}_{2} \mathrm{O} \\
15 \mathrm{~min} \text { shaking }\end{array}$ & $\begin{array}{l}\text { 2. } 20 \mathrm{ml} \mathrm{H}_{2} \mathrm{O} \\
15 \text { min shaking }\end{array}$ & $\begin{array}{l}\text { 2. } 20 \mathrm{ml} \mathrm{H}_{2} \mathrm{O} \\
15 \mathrm{~min} \text { shaking }\end{array}$ \\
\hline
\end{tabular}

\subsection{Gel electrophoresis}

Control and treated membranes were solubilized in $2 \%$ SDS dissolved in $50 \mathrm{~mm}$ $\mathrm{Na}_{2} \mathrm{CO}_{3}-50 \mathrm{~mm}$-DTT. In some instances $5 \%$ mercaptoethanol was also added. Gel electrophoresis was performed using the conditions described by CHUA and BENNOUN (5).

\subsection{Electron microscopy}

Membranes were sampled for fixation by plunging a Pasteur pipette into the pellet obtained after the final centrifugation and extruding the core of collected material into $1 \%$ buffered glutaraldehyde, as described by HøYER-HANSEN and SIMPSON (8). Membrane samples for freeze-fracturing were taken from the same unfixed pellet and frozen in $25 \mathrm{~mm}$ HEPES, $10 \mathrm{~mm}$-EDTA (control) or distilled water (treated material) using Freon 22 cooled in liquid nitrogen. Replicas were prepared according to standard procedures on a Balzers
BAF 301 freeze-etching machine (Balzers Aktiengesellschaft, Liechtenstein). Specimens were freeze-fractured at $-110^{\circ} \mathrm{C}$ and etching was carried out at $-100^{\circ} \mathrm{C}$ for $2 \mathrm{~min}$.

\subsection{Lipid and fatty acid analysis}

Lipids were extracted from purified thylakoids and analyzed by thin-layer chromatography and gas-liquid chromatography as described in (2).

\section{RESULTS}

Thin sections of the purified wild-type membranes after glutaraldehyde-osmium fixation revealed discrete lamellar systems of destacked thylakoids. Figure 1 gives a typical field of a sectioned membrane preparation and illustrates its high purity. Freeze-fracturing of these membranes revealed the two characteristic fracture faces of destacked thylakoids (STAEHELIN, 15). 
The fracture face next to the thylakoid lumen (endoplasmic face - EF) exhibited large particles and that next to the stroma (protoplasmic face - PF), a dense population of small particles (Fig. 2). In many regions of the membranes, the particles of both the EF and PF faces were present in linear arrays (Fig. 2). The two etched surfaces (ES and PS) of purified membranes were devoid of particles (Fig. 3), whereas the surfaces of unpurified barley thylakoid membranes did exhibit particles, in agreement with the results of MILLER and STAEHELIN (12) for spinach.

A typical gel pattern of the polypeptides found in the purified thylakoid preparations is reproduced in Figure 4 . The polypeptides of chlorophyll-protein complex I (CPI) and chlorophyll-protein complex II (CPII) as well as its apoprotein (CPII-AP) are indicated. Additional typical chloroplast membrane polypeptides are evident in the pattern. The presence of considerable amounts of the two large coupling factor subunits $\left(\mathrm{CF}_{1}\right)$ is surprising in view of the absence of particles from the PS face, where coupling factor is supposedly visible. Further investigations of the conditions which lead to the disappearance of particles from the freezeetch surfaces are necessary.

Treatment of thylakoids with either trypsin or subtilisin, followed by $8 \mathrm{M}$-urea extraction to remove proteolytic enzyme molecules adhering to the membranes, preserved the basic structure of the membranes, as judged by thin sectioning (Figs. 5 and 7). Both treatments resulted in the formation of uniformly sized, regularly shaped vesicles. This membrane vesiculation may not be exclusively due to the action of the enzymes, since the forces generated during vigorous shaking of membranes in water also caused the membranes to form vesicles.
The freeze-fracture appearance of vesicles obtained by enzyme treatment is shown in Figures 6 and 8. Two different types of faces were seen in both treatments; convex fracture faces with a high concentration of particles per unit area, and concave fracture faces with few particles. Based on the assumption that the vesicles retain their original orientation with respect to the sidedness of thylakoids, the concave faces must be considered to be PF faces and, similarly, the convex faces should be EF faces. The lower concentration of particles on the concave (PF) faces compared with the convex faces implies that trypsin and subtilisin treatment affected the way in which particles cleave during freeze-fracturing. Another characteristic effect of the protease treatment was the reduction in the average size of the freeze-fracture particles. Either the large particles of the EF face of untreated thylakoids have been reduced in size or are altogether absent.

In spite of the similar appearance of the freeze-fracture faces of trypsin and subtilisin treated membranes, there were significant differences with respect to the polypeptide patterns (Fig. 4). The trypsin incubated material showed the green bands of the chlorophyllprotein complexes which run with a slightly higher electrophoretic mobility (Fig. 4d). The polypeptide bands normally found between the two complexes were missing from the pattern. The bands present in the lower part of the gel may represent components deeply embedded in the lipid matrix of the membrane and therefore inaccessible to trypsin attack. The polypeptide pattern from subtilisin treated thylakoids contained three prominent bands, two of which were green and corresponded to the chlorophyll-protein complexes with altered mobility (Fig. 4f). The third band had a high

Figure 1. Representative field of the purified thylakoid pellet from isolated wild-type barley chloroplasts. $\times 12,100(\mathrm{Bar}=2 \mu \mathrm{m})$.

Figure 2. Freeze-fractured destacked wild-type thylakoids, corresponding to those seen fixed and thin-sectioned in Figure 1. Note the formation of particle arrays in both EF and PF faces. $\times 68,400(\mathrm{Bar}=1 \mu \mathrm{m})$. 


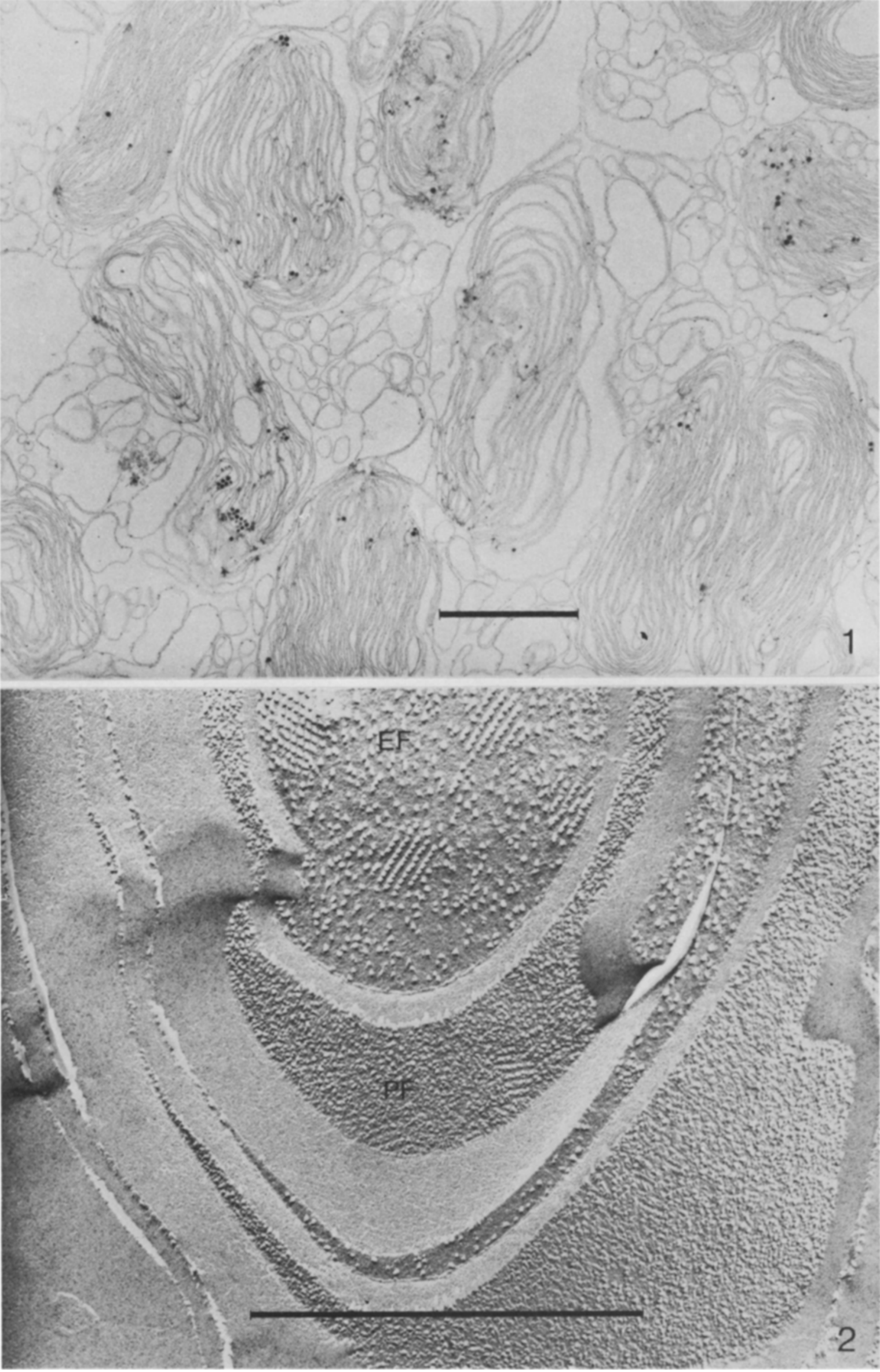




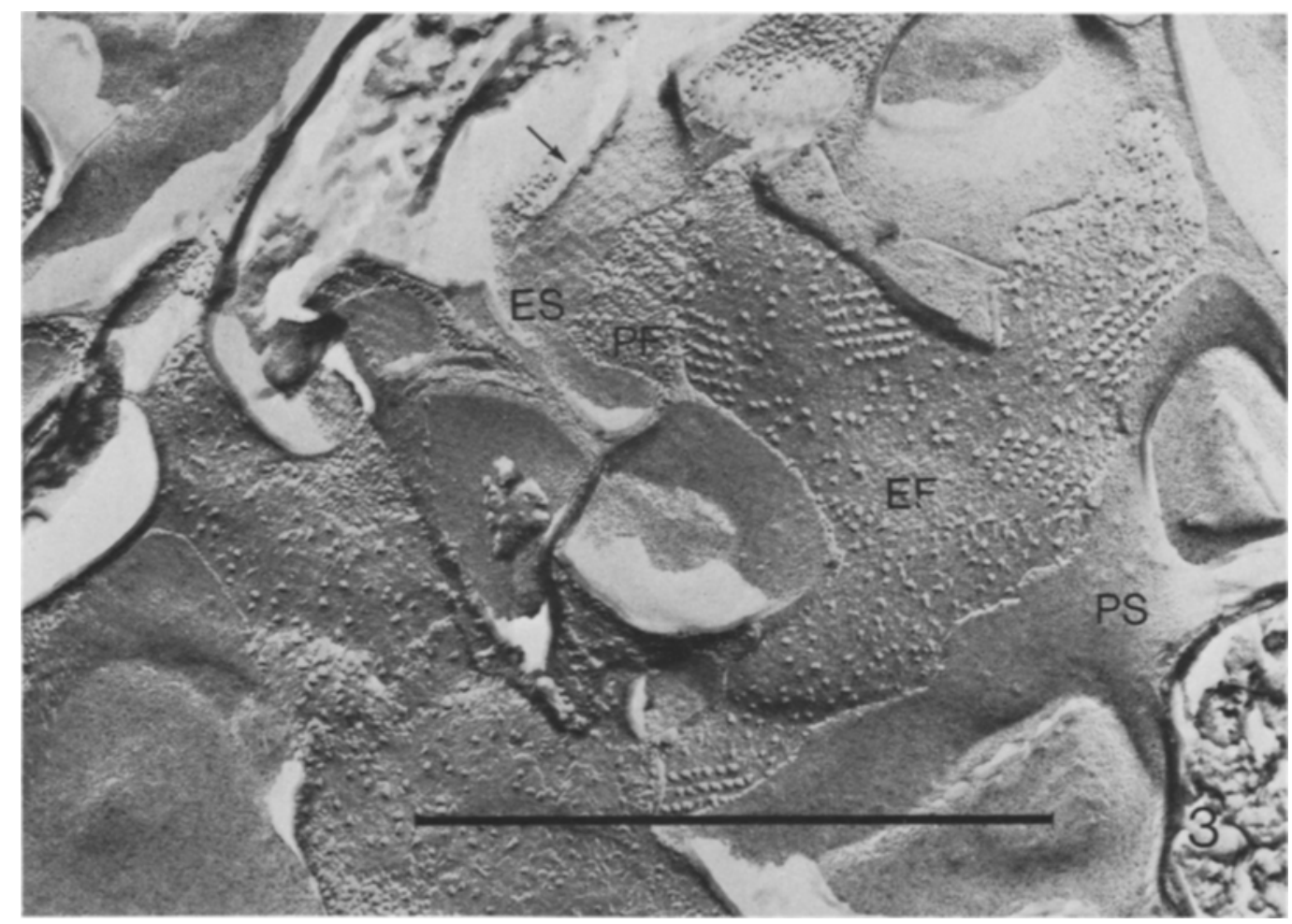

Figure 3. Freeze-fractured thylakoids from the same preparation as in Figure 2, etched for 2 min at $-100^{\circ} \mathrm{C}$. Note the absence of particles visible on the ES and PS surfaces, although there seem to be ridges (arrow) on the ES surface, corresponding to the PF arrays. $\times 68,400(\mathrm{Bar}=1 \mu \mathrm{m})$.

electrophoretic mobility. After addition of $5 \%$ mercaptoethanol to the solubilized membranes practically all polypeptide material appeared at the position of this third band (Fig. 4e). The latter is considered to contain chlorophyll-protein complex fragments protected by their position in the membrane against subtilisin attack. The presence of chlorophyll protein complexes in the gels after subtilisin treatment (Fig. 4f) can be explained by the presence of disulphide bridges and their disappearance after addition of mercaptoethanol by the reduction of the disulphide bridges. Therefore the presence of freeze-fracture particles after trypsin or subtilisin digestion correlates with the preservation of the chlorophyll-protein complexes in the membrane prior to solubilization. The disappearance of the large freeze-fracture particles after protease treatment may or may not be related to the absence of other polypeptides.
Membrane vesicles were also found in thin sections of thylakoids treated for $3 \mathrm{~h}$ with $6 \mathrm{M}$ guanidine- $\mathrm{HCl}$ followed by extraction with $8 \mathrm{M}$ urea (Fig. 9). These membranes cleaved normally during freeze-fracturing, revealing intramembraneous particles (Fig. 10). As with trypsin and subtilisin treatments, it was difficuit to correlate the freeze-fracture faces of guanidine- $\mathrm{HCl}$ treated thylakoids with the EF and PF faces of the control membranes. Most, if not all, of the vesicles had regular arrays of particles on both concave and convex faces. Generally, these arrays were located at constrictions of the vesicles. Small vesicles had one constriction and larger ones had two or three. The centre-to-centre distances between the particles in the arrays were approximately $100 \mathrm{x}$ $160 \AA$. This compares with values of $180 \times 240 \AA$ measured for the EF arrays of the untreated thylakoids. No large freeze-fracture particles, 

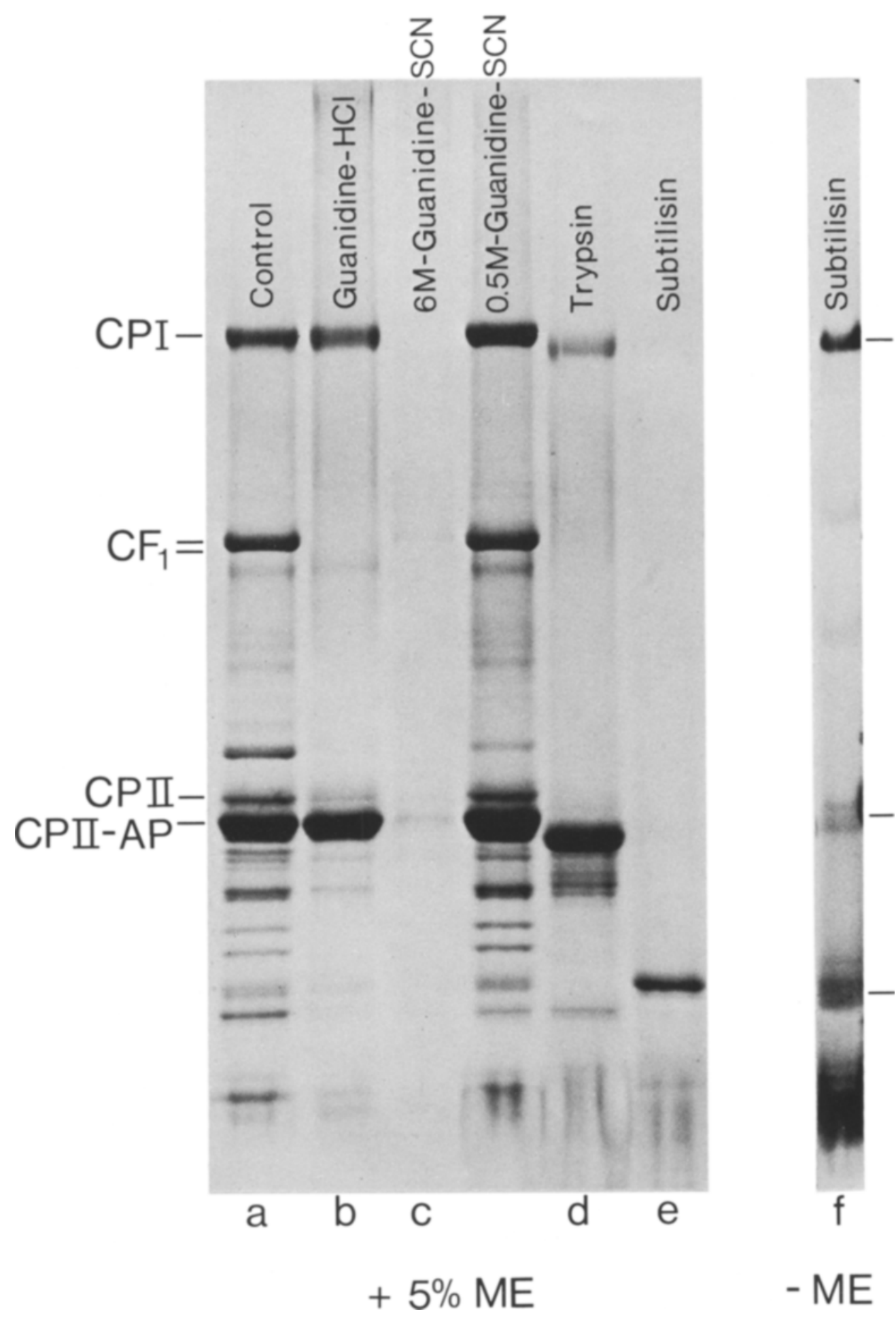


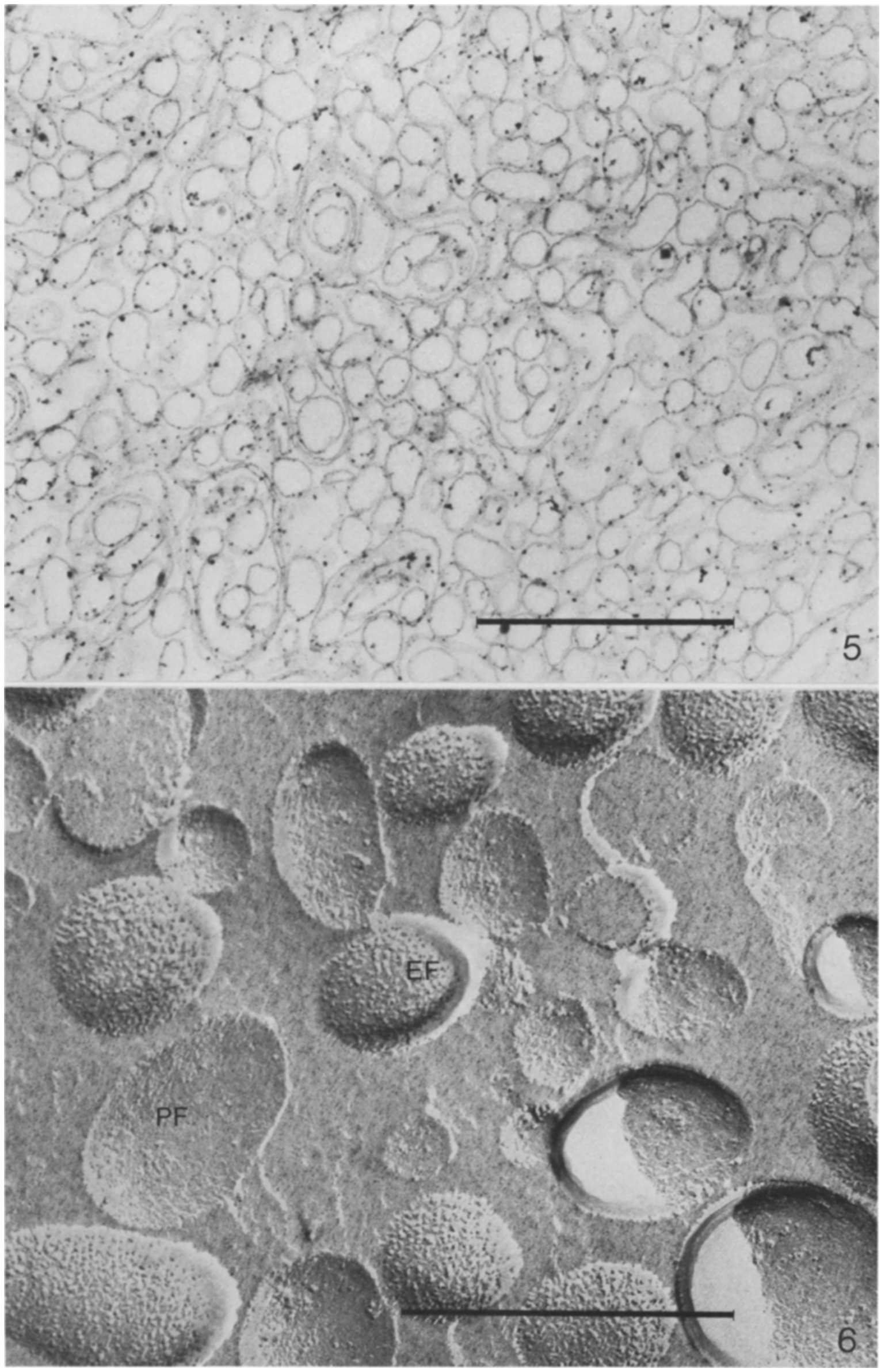




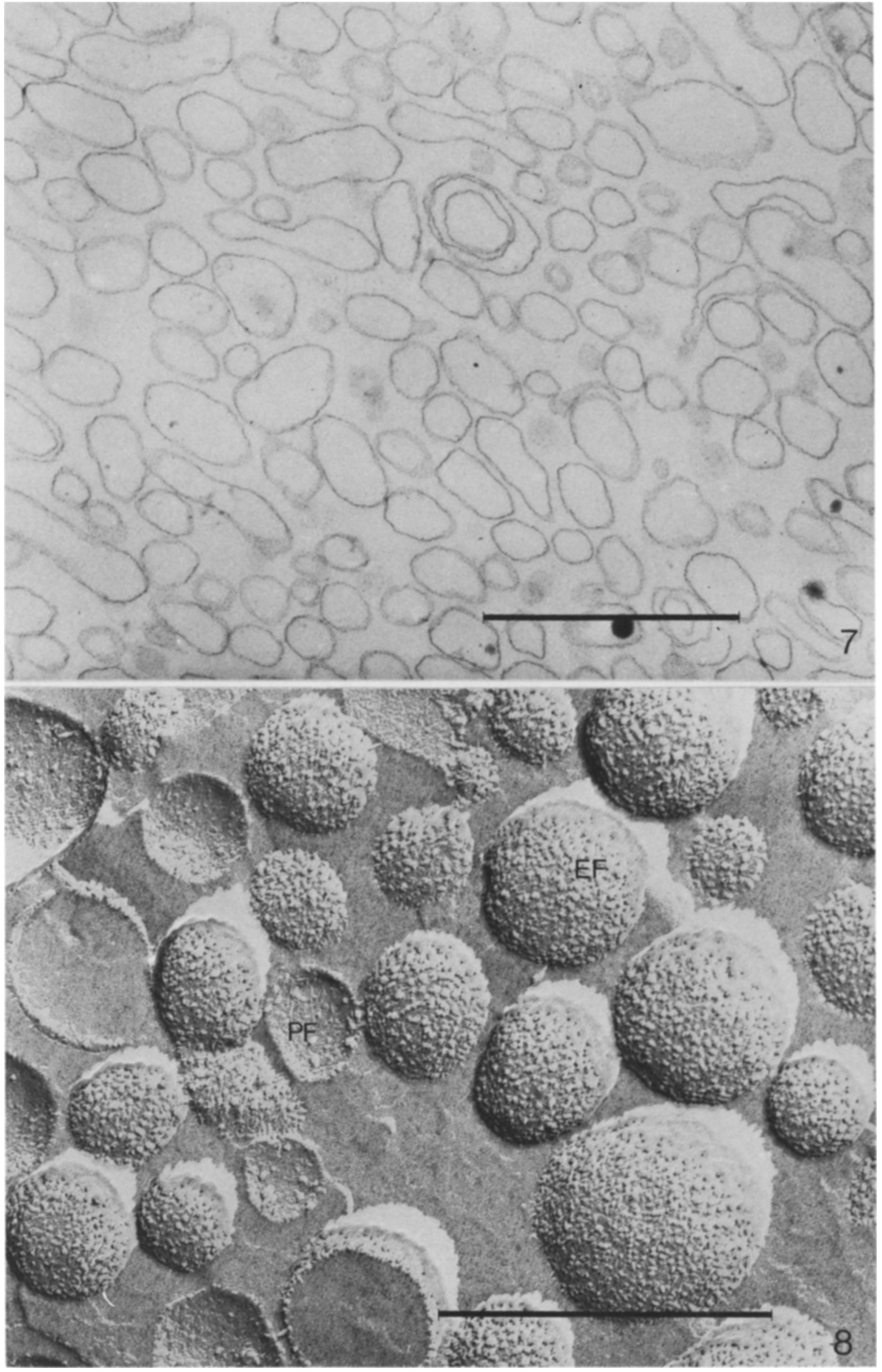


Figure 4. Gel electrophoretogram of the polypeptides present in purified wild-type thylakoids after different treatments. The chlorophyll-protein complexes are present after all treatments, except that with $6 \mathrm{M}$-guanidine thiocyanate, which also destroys the membrane structure. After trypsin digestion, both CPI and CPII-AP have an increased electrophoretic mobility, and after incubation with subtilisin the complexes are only seen when mercaptoethanol is omitted.

Figure 5. Thin section of the thylakoid vesicles resulting from trypsin treatment. $\times 44,900(\mathrm{Bar}=1 \mu \mathrm{m})$.

Figure 6. Freeze-fracture of the trypsinized thylakoids demonstrating preservation of membrane integrity and revealing particles on both fracture faces. $\times 116,000(\mathrm{Bar}=0.5 \mu \mathrm{m})$.

Figure 7. Thin-sectioned membranes after incubation of thylakoids with subtilisin. $\times 44,900(\mathrm{Bar}=1 \mu \mathrm{m})$.

Figure 8. Freeze-fracture appearance of subtilisin-treated thylakoids. $\times 116,000(\mathrm{Bar}=0.5 \mu \mathrm{m})$.

corresponding to the large EF particles of the control membranes, were found on either of the fracture faces of guanidine- $\mathrm{HCl}$ treated thylakoids.

The electrophoretic pattern of guanidine$\mathrm{HCl}$ treated membranes contained both chlorophyll-protein complexes in amounts equivalent to untreated membranes on a chlorophyll basis (Fig. 4b). In contrast to the trypsin treated membranes, the mobility of the complexes did not change and there were two polypeptide bands between the complexes. Some of the polypeptides in the lower part of the gel were also present after $3 \mathrm{~h}$ of extraction (Fig. 4b).

Treatment of membranes with $6 \mathrm{M}$-guanidine thiocyanate, which is known to be a potent chaotropic agent, resulted in their complete disintegration after only $10 \mathrm{~min}$ of shaking. No membranes were visible in the thin sections of the pelleted residue remaining after extraction (Fig. 11), which consisted of black deposits and short, electron-dense rods surrounded by an electron-transparent region, seen in longitudinal and transverse section in Figure 11. When this material was freeze-fractured, similar short rod-like structures were also found (Fig. 12). In addition, parts of the sample behaved during freeze-fracturing in the same way as pure lipid bilayers with a spacing of $65 \AA$ within the fracture plane (Fig. 13) and may correspond with the areas of electron-dense material in thin sections. The lipid and fatty acid composition of the residue remaining after guanidine thiocyanate extraction were identical to those of the control thylakoids, so no lipids were selectively removed during the treatment. Chlorophyll was present in the pelleted material as well as in small vesicles arising from the lipids, as determined by incident fluorescence light microscopy.

The polypeptide pattern of the guanidine thiocyanate extracted membranes was consistent with electron microscope results. The protein content was very low, with only a few weak bands in the electrophoretic pattern (Fig. 4c). This treatment thus removed the chlorophyll-protein complexes from the thylakoids, but the membrane structure was destroyed in the process.

The major proteins of wild-type basic membranes were chlorophyll-protein complexes I and II, which could not be removed without destroying the membrane structure. The chlorophyll $b$-less mutant chlorina- $f 2$ contains thylakoids which lack CPII and thus offers the possibility to study the response of a membrane deficient in a major polypeptide to various treatments.

Chlorina -22 membranes isolated and purified according to the same procedure used for wildtype membranes yielded fragmented thylakoids. Freeze-fracturing of these thylakoids revealed the usual EF and PF faces (Fig. 14) containing particles distributed in a similar manner to wild-type. A comparison of the gel pattern of the polypeptides of these membranes with those of wild-type confirmed the absence of chlorophyll-protein complex II (Fig. 15).

After $3 \mathrm{~h}$ extraction with $6 \mathrm{M}$-guanidine- $\mathrm{HCl}$ 


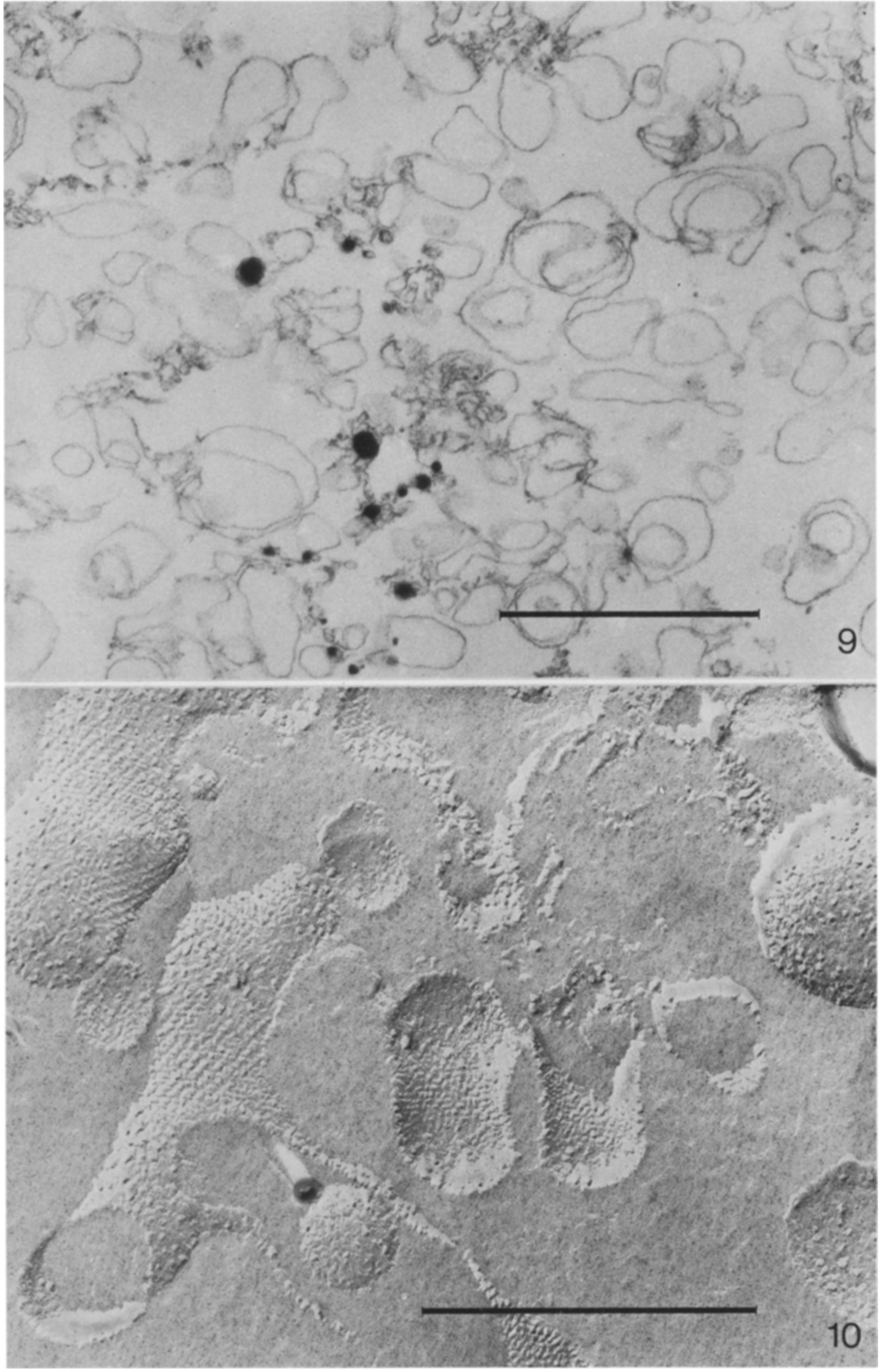


Figure 9. Thin-sectioned guanidine- $\mathrm{HCl}$ treated thylakoids. The electron dense areas may indicate a slight degree of membrane disintegration. $\times 44,900(\mathrm{Bar}=1 \mu \mathrm{m})$.

Figure 10. Freeze-fracture appearance of guanidine- $\mathrm{HCl}$ extracted thylakoids. Both concave and convex faces contain particle arrays in constricted regions of the vesicles and it is not possible to distinguish EF and PF faces. $\times 116,000(\mathrm{Bar}=0.5 \mu \mathrm{m})$.

freeze-fracturing revealed that many of the thylakoids had been modified so that they no longer directed the fracture plane between the two layers of the lipid bilayer. Most of the material resembled that shown in Figure 16, although there were also smoothly fractured membranes containing very few particles on either the concave or convex face (Fig. 17). After $6 \mathrm{~h}$ of extraction, no membrane-like fracture faces were found, and some material was present as crystalline lipids, similar to those shown in Figure 12, indicating further disruption of the membrane structure.

The polypeptide pattern of chlorina- 2 thylakoids extracted for $3 \mathrm{H}$ with guanidine- $\mathrm{HCl}$ resembled those of similarly treated wild-type membranes, except for the expected absence of chlorophyll-protein complex Il (Fig. 15).

\section{DISCUSSION}

The results show that proteases or guanidine$\mathrm{HCl}$ can remove large amounts of protein from barley thylakoids without destroying membrane structure. Moreover, many polypeptides are extracted specifically, which produces membranes with a polypeptide composition simpler than that of untreated thylakoids. This confirms previous results obtained with Vicia faba and Acetabularia $(1,10,16)$. Because membrane structure is preserved, as judged by thin-sectioning and freeze-fracturing, it is possible to draw certain conclusions with respect to the location of polypeptides within the thylakoids, and to make correlations between polypeptide composition and freeze-fracture particles.

Limited proteolysis of membrane polypep- tides by trypsin and subtilisin indicates that both chlorophyll-protein complexes are at least partially accessible to these enzymes, since these polypeptides have a slightly lower molecular weight after protease incubation. This agrees with the findings of Suss et al. (16) who found an increased electrophoretic mobility of chlorophyll-protein complex II after trypsin digestion of Vicia faba thylakoids.

In contrast to the chlorophyll-protein complexes, many other polypeptides are completely removable by proteolysis with or without a subsequent extraction in $8 \mathrm{M}$-urea. This could mean that the latter polypeptides are readily accessible at the surface of the membrane.

The specific removal of polypeptides other than the chlorophyll-protein complexes by proteases results in an alteration of the appearance of the two observable freeze-fracture faces. On the EF face large particles are no longer visible and the face exhibits a dense population of small particles. On the PF face a dense population of small particles has been replaced by a sparse population. Thus the presence of chlorophyll-protein complexes $\mathbf{I}$ and II is not a sufficient condition to give large freeze-fracture particles.

There are several possible explanations for the altered particle sizes and their distribution between the two faces. 1) The large particles are removed by proteolysis and the membrane altered in such a way that cleavage results in appearance of many small particles on the EF face. This explanation would imply that chlorophyll-protein complex II could not be a component of the large particles. 2) Removal of some of the polypeptides results in a reduction

Figure 11. Thin-section of the pelletable material after extraction of thylakoids with $6 \mathrm{M}$-guanidine thiocyanate. Much of the material is present in the form of rods. $\times 116,000(\mathrm{Bar}=0.5 \mu \mathrm{m})$.

Figure 12. Freeze-fracture appearance of the rods seen in Figure 11. $\times 116,000(\mathrm{Bar}=0.5 \mu \mathrm{m})$. 


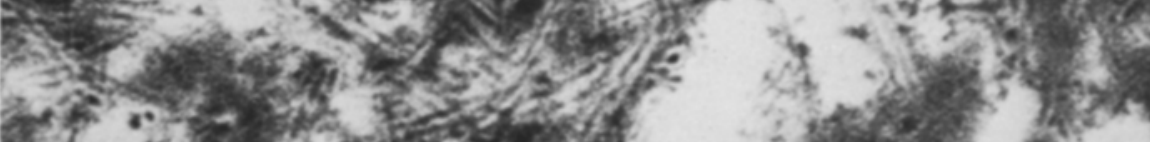

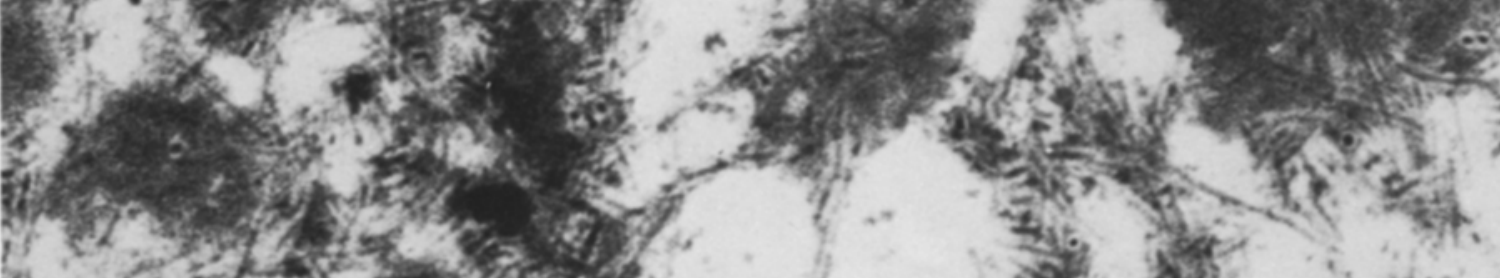
P.

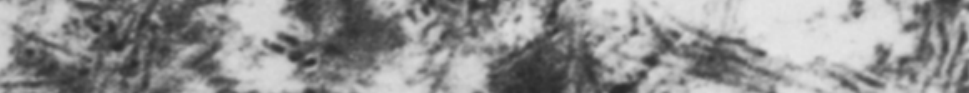
(n) in

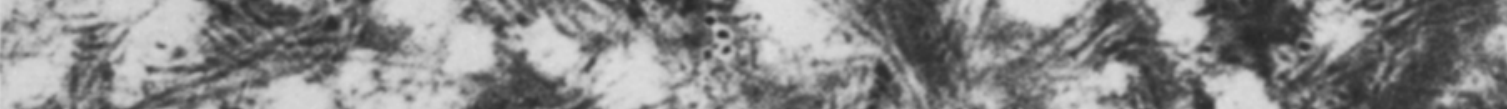
s.

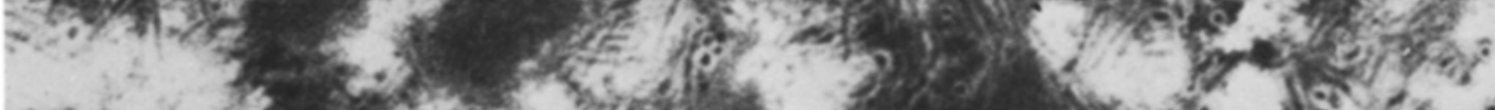

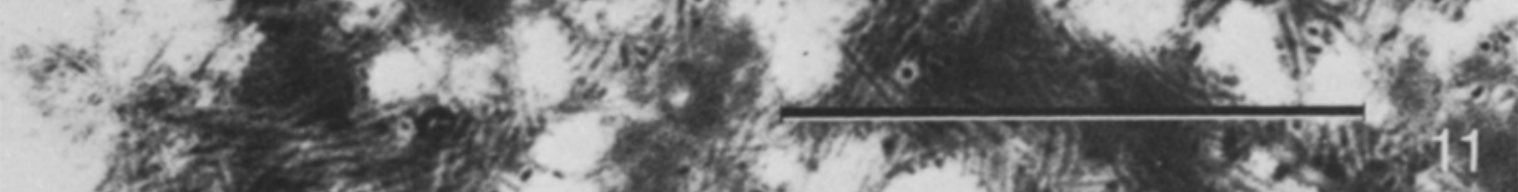

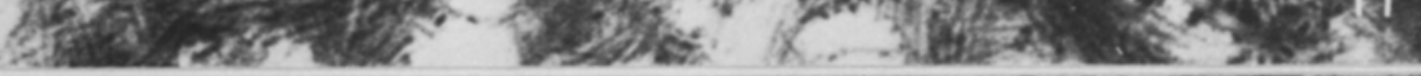

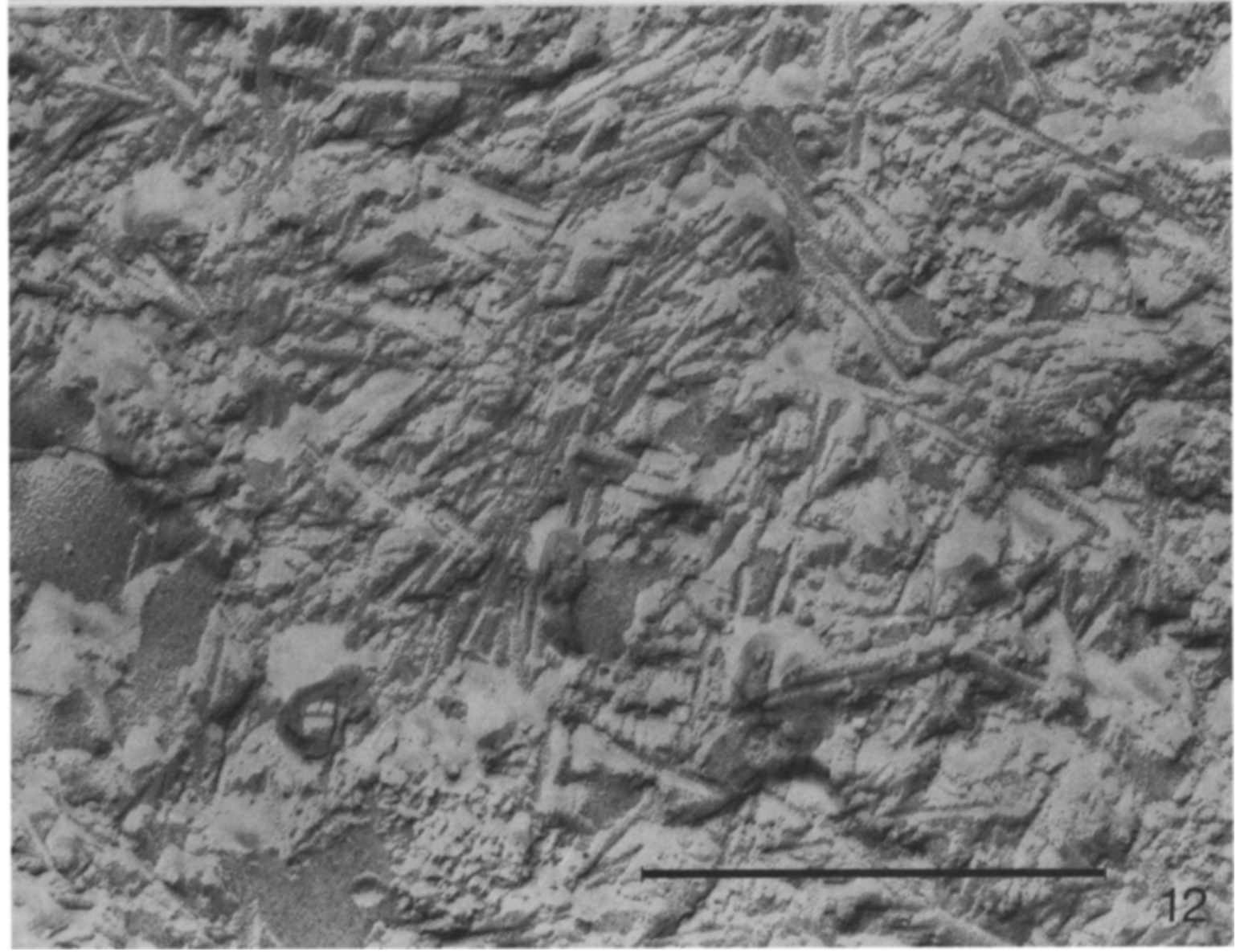




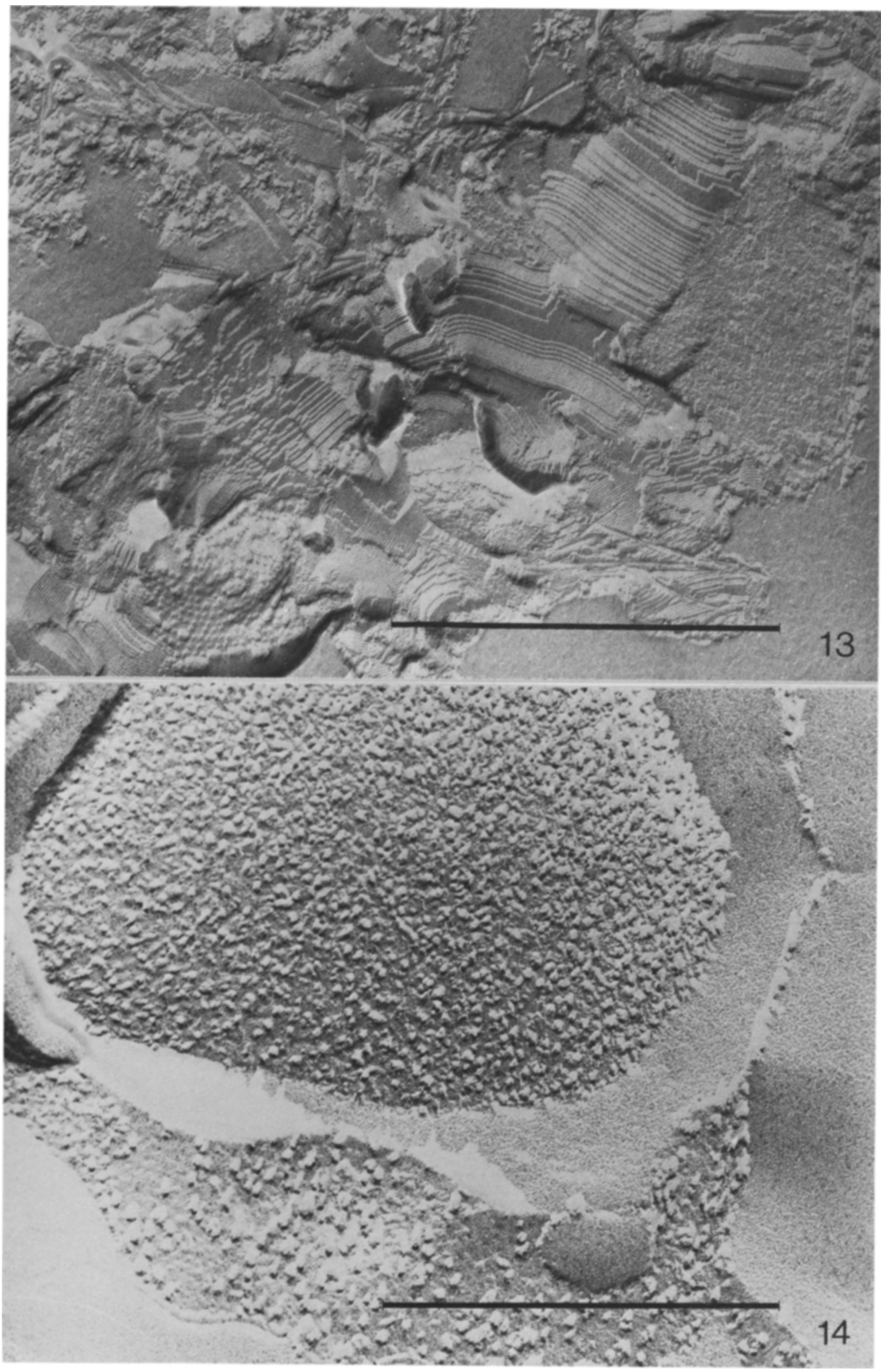


Figure 13. Freeze-fracture replica of $6 \mathrm{M}$-guanidine thiocyanate treated thylakoids resembling lipid bilayers. $\times 68,400($ Bar $=1 \mu \mathrm{m})$.

Figure 14. Freeze-fracture appearance of destacked, purified thylakoids from chlorina- 2 chloroplasts, showing EF and PF faces. $x 136,000($ Bar $=0.5 \mu \mathrm{m})$.

of the size of the large particles in combination with an alteration in the cleavage behaviour again resulting in the appearance of many small particles on the EF face. 3) Proteolysis results in the dissociation of the large particles into their four subunits (11) and concomittant disappearance of the small particles normally present on the PF face. This implies and these small particles are no longer visible in spite of the presence of chlorophyll-protein complex I.

Treatment of thylakoids of Acetabularia (1) with pronase resulted in extensive removal of polypeptides other than chlorophyll-protein complexes. APEL et al. found the two freezefracture faces altered after pronase treatment in a similar manner as reported here for barley with trypsin or subtilisin. One face showed a few small particles, whereas the other revealed a dense population of small particles. The designation of these faces was based on the particle density, implying that the densely populated face was an unaltered PF face and the sparsely populated an EF face with reduced particle size. It is, however, possible that in Acetabularia pronase treatment altered the fracture behaviour of the membrane and the face designated as PF would then be an EF face and vice versa.

Treatment with guanidine- $\mathrm{HCl}$ produces membranes which contain the chlorophyllprotein complexes with unaltered electrophoretic mobility as the major polypeptide components. In this case the two fracture faces looked alike and were differentiated into areas containing dense arrays of small particles and less densely populated areas. The chlorophyllprotein complexes must be major components of the particles made visible by freeze-fracturing membranes after treatment with proteases or guanidine- $\mathrm{HCl}$ since they comprise an enhanced proportion of the membrane protein moiety compared to untreated membranes. The particles contain several polypeptide chains (cf. 7). The differences in the freeze-fracture appearance of protease treated and guanidine$\mathrm{HCl}$ extracted membranes can be the result of differences in the structure of chlorophyllprotein complexes or differences in minor peptides present in the particles or a combination of these two effects.

Treatment with guanidine thiocyanate yielded macromolecular lipid complexes devoid of particles after freeze-fracturing. Thus a treatment of the membranes which removes the chlorophyll-protein complexes also disrupts the membrane structure. The lipid complex had tubular and lamellar organization reminiscent of the complexes obtained with artificial mixtures of lipid in water (9). The repeat distance of $65 \AA$ of the lines visible within the plane of a fracture face of a lamellar complex (Fig. 12) in our preparations is consistent with the spacing of the rods of the hexagonal II phase determined on the liquid-crystalline monogalactosyl diglyceride-water system by SHIPLEY et al. (13) using X-ray diffraction and freeze-etching. Monogalactosyl diglycerides from the chloroplast membranes are also a major component of the lipid complexes studied in this paper.

\section{ACKNOWLEDGEMENTS}

We thank professor DITER vON WETTSTEIN for valuable discussions and critical reading of the manuscript, Dr. C. Gamini Kannangara for performing the lipid and fatty acid analyses, and Dr. IB SVENDSEN for kindly providing the subtilisin. We are grateful for the skilful technical assistance of JEAN SAGE and ANNSofI STEINHOLTz. Financial support was provided by Commission of the European Communities contract 029-76-ES DK solar energy program and by USPHS, National Institutes of Health (GM-22051). 


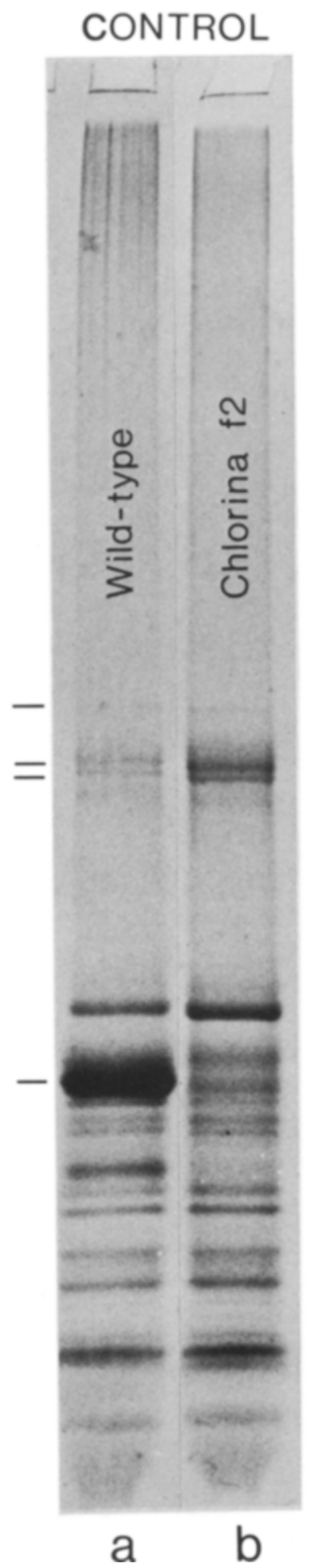

\section{CHLORINA f2}

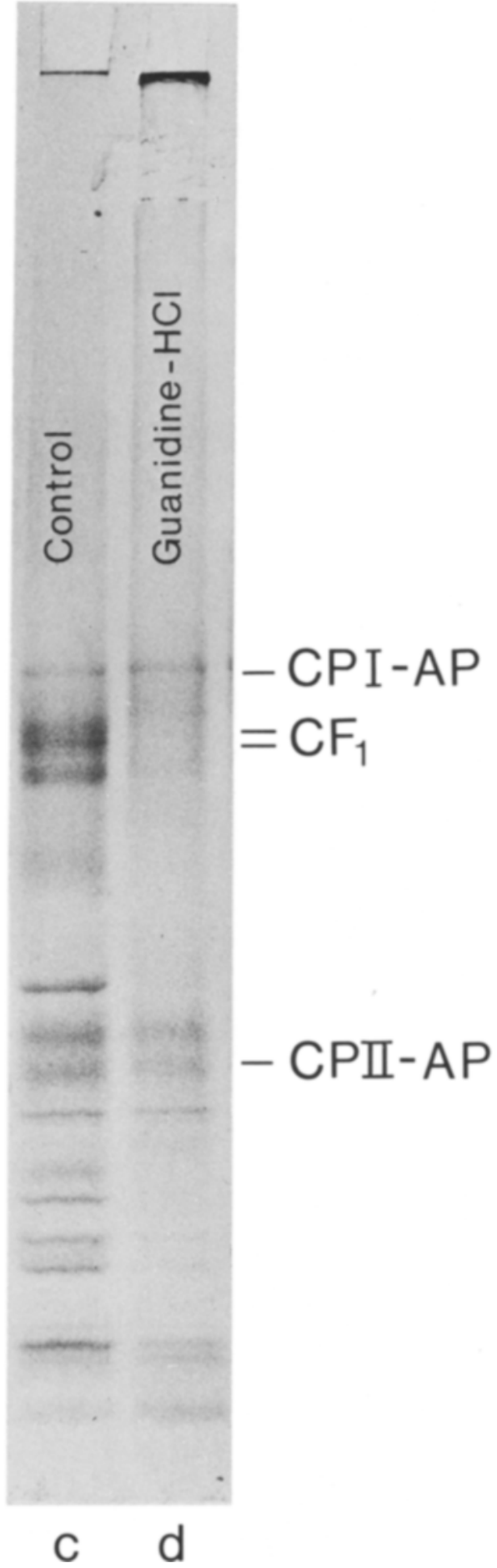

Figure 15. Gel electrophoretogram of the polypeptides of chlorina- 2 thylakoids and the effect of treatment with guanidine- $\mathrm{HCl}$. The major difference between the chlorina- $f 2$ membranes and similarly treated wild-type thylakoids is the absence of CPII. 

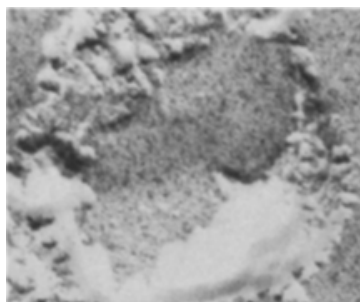

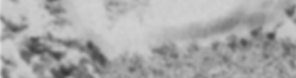

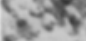

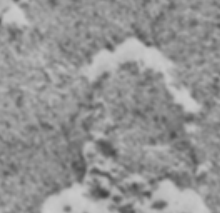

sin

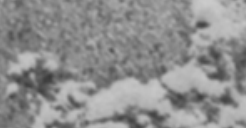

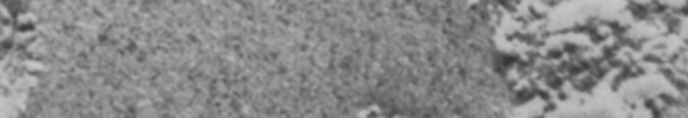
inens

क. -40 at

$x_{x \rightarrow 2}+\infty$

$4 x^{2} x^{2}$

$3 x+23$

Ats.

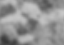
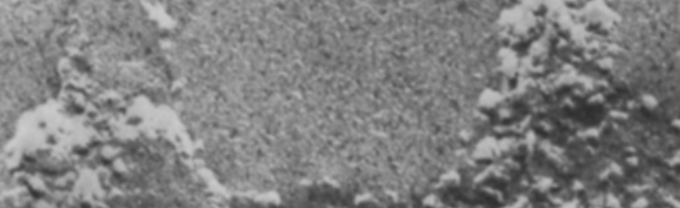

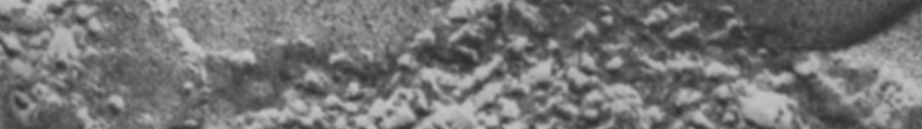

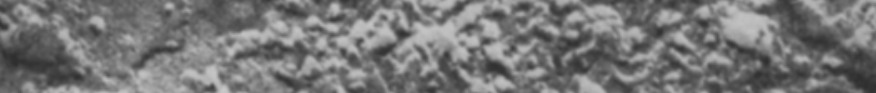

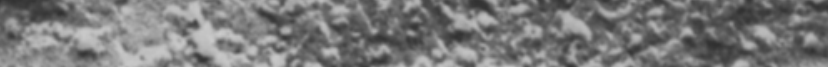

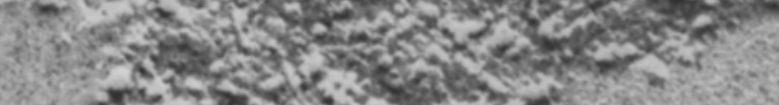

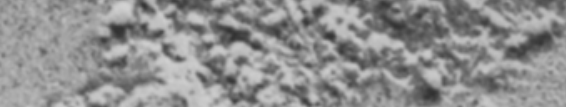

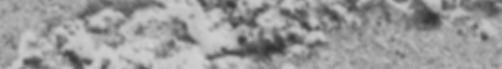

$$
\begin{aligned}
& \text { on } \\
& c^{2}+3
\end{aligned}
$$

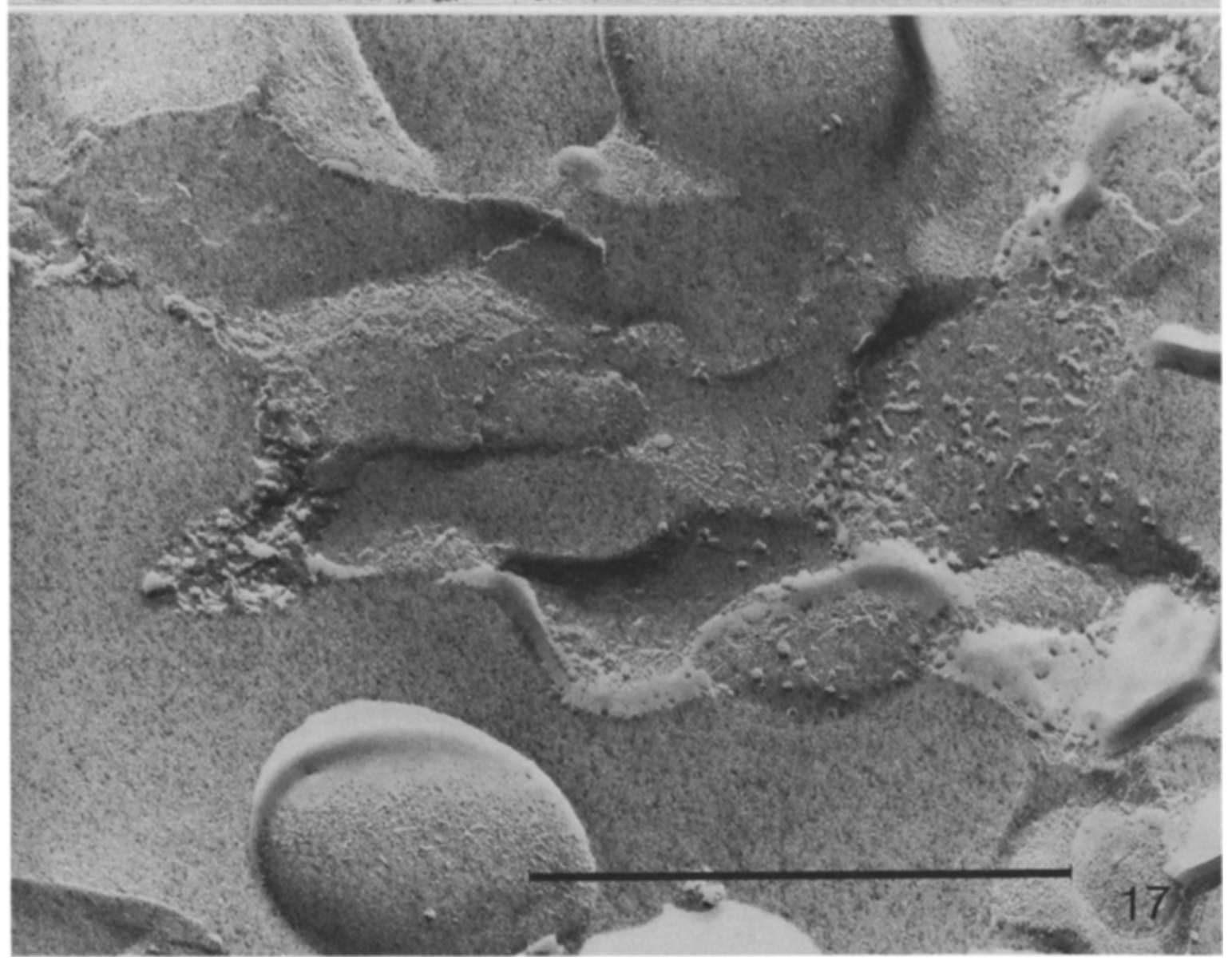


Figure. 16 Freeze-fracture appearance of chlorina- 2 thylakoids treated with guanidine-HCl for 3 hours. The membranes no longer seem to direct the plane of fracture and the exposed faces are uneven, although freezefracture particles may be present. $\times 136,000(\mathrm{Bar}=0.5 \mu \mathrm{m})$.

Figure 17. As in Figure 16, showing thylakoid regions that have fractured more normally, revealing a low density of freeze-fracture particles. $\times 136,000(\mathrm{Bar}=0.5 \mu \mathrm{m})$.

\section{REFERENCES}

1. Apel, K., K. R. Miller, L. Bogorad \& G. J. MILLER: Chloroplast membranes of the green alga Acetabularia mediterranea II. Topography of the chloroplast membrane. J. Cell Biol. 71, 876-893 (1976)

2. Appelqvist, L. -A., J, E. Boynton, P. K. Stumpf \& D. VON WETTSTEIN: Lipid biosynthesis in relation to chloroplast development in barley. $\mathrm{J}$. Lipid Res. 9, 425-436 (1968)

3. Arntzen, C. J., R. A. Dilley \& F. L. Crane: A comparison of chloroplast membrane surfaces visualized by freeze-etch and negative staining techniques; and ultrastructural characterization of membrane factions obtained from digitonintreated spinach chloroplasts. J. Cell Biol. 43, $16-$ 31 (1969)

4. Branton, D., S. Bullivant, N. B. Gilula, M. J. Karnovsky, H. MoOr, K. Múhlethaler, D. H. Northcote, L. Packer, B. Satir, P. Satir, V. Speth, L. A. Staehelin, R. L. Steere \& R. S. WEINSTEIN: Freeze-etching nomenclature. Science 190, 54-56(1975)

5. Chua, N. -H. \& P. Bennoun: Thylakoid membrane polypeptides of Chlamydomonas reinhardi: Wild-type and mutant strains deficient in photosystem Il reaction center. Proc. Nat. Acad. Sci. USA 72, 2175-2179 (1975)

6. Grant, C. W. M. \& H. M. McConnell: Glycophorin in lipid bilayers. Proc. Nat. Acad. Sci. USA 71, 4653-4657 (1974)

7. Fisher, K. A. \& W. Stoeckenius: Freeze-fractured purple membrane particles: protein content. Science 197, 72-74 (1977)

8. Høyer-Hansen, G. \& D. J. Simpson: Changes in the polypeptide composition of internal membranes of barley plastids during greening. Carlsberg Res. Commun. 42, 379-389 (1977)

9. LuCY, J. A. \& A. M. Glauert: Structure and assembly of macromolecular lipid complexes composed of globular micelles. J. Mol. Biol. 8, 727-748 (1964)
10. MACHOLD, O:: On the molecular nature of chloroplast thylakoid membranes. Biochim. Biophys. Acta 382, 494-505 (1975)

11. MiLler, K. R.: A particle spanning the photosynthetic membrane. J. Ultrastruct. Res. 54, 159-167 (1976)

12. Miller, K. R. \& L. A. Staehelin: Analysis of the thylakoid outer surface. Coupling factor is limited to unstacked membrane regiops. J. Cell Biol. 68, 30-47 (1976)

13. Shipley, G. G., J. P. Green \& B. W. Nichols: The phase behaviour of monogalactosyl, digalactosyl and sulphoquinovosyl diglycerides. Biochim. Biophys. Acta 311, 531-544 (1973)

14. Singer, S. J. \& G. L. Nicholson: The fluid mosaic model of the structure of cell membranes. Science 175, 720-731 (1972)

15. Staehelin, L. A.: Reversible particle movements associated with unstacking and restacking of chloroplast membranes in vitro. J. Cell Biol. 71 , 136-158 (1976)

16. Súss, K. -H., O. Schmidt \& O. MAchold: The action of proteolytic enzymes on chloroplast thylakoid membranes. Biochim. Biophys. Acta 448, 103-113 (1976)

17. Thornber, J. P., J. C. Stewart, M. W. C. HatTon \& J. L. Balley: Studies on the nature of chloroplast lamellae. II. Chemical composition and further physical properties of two chlorophyll-protein complexes. Biochemistry 6 , 2006-2014 (1967)

18. Yu, J., \& D. Branton: Reconstitution of intramembrane particles in recombinants of erythrocyte protein Band 3 and lipid: Effect of spectrin-actin association. Proc. Nat. Acad. Sci. USA 73, 3891-3895 (1976) 